\title{
Funcionalidade dos sistemas financeiros e o financiamento a pequenas e médias empresas: $o$ caso do crowdfunding
}

\author{
Norberto Montani Martins* \\ Pedro Miguel Bento Pereira da Silva**
}

\begin{abstract}
Resumo: O presente artigo analisa a relação entre a funcionalidade do sistema financeiro e o financiamento coletivo através da Internet (crowdfunding), destacando o papel que este arranjo de financiamento pode exercer na obtenção de recursos por pequenas e médias empresas para levar a cabo seus projetos e negócios. Também são analisados os possíveis riscos associados a esta forma de financiamento, especialmente quando pressupõe retorno financeiro, o que revela a necessidade de um arcabouço regulatório dedicado.Por fim, discute-se a importância da construção de uma agenda de pesquisa sobre o tema no Brasil.
\end{abstract}

Palavras-chave: Sistema Financeiro. Funcionalidade. Crowdfunding. Inclusão Financeira. Regulação Financeira. Proteção do Investidor.

Classificação JEL: G23; G24; G28; G18; O16; O31.

\begin{abstract}
This paper analyses the relationship between crowdfunding and financial system's functionality. Crowdfunding could help small and medium entrepreneurs and enterprises (SMEs) in accessing finance, typically restricted for them in the context of the traditional financial system, and conduct their activities, business and projects. However crowdfunding, especially in its financial return form, poses some risks and regulatory challenges, which need to be addressed. Finally, we discuss the relevance of setting a research agenda about this issue in Brazil.
\end{abstract}

Keywords: Financial System. Functionality. Crowdfunding. Financial Inclusion. Financial Regulation. Investor Protection.

\section{Introdução}

A dificuldade de acesso de pequenas e médias empresas e de empreendedores individuais ao financiamento apropriado é notável e reconhecida pela teoria e prática econômicas. Do ponto de vista prático, por exemplo, a Comissão Europeia (2011: 1) reconhece que:

"Europe's economic success depends largely on the growth of Small and Medium sized Enterprises (SMEs) achieving their potential. SMEs contribute more than half of the total value added in the non-financial business economy and provided $80 \%$ of all new jobs in Europe in the past five years.

SMEs often face significant difficulties in obtaining the financing they need in order to grow and innovate."

Do ponto de vista teórico, por sua vez, a teoria Keynesiana aponta, como um desdobramento dos elementos característicos das economias monetárias de produção, a restrição do acesso destes

\footnotetext{
*Mestre em Economia, Universidade Federal do Rio de Janeiro. Pesquisador do Grupo de Estudos sobre Moeda e Sistema Financeiro.

${ }^{* *}$ Mestre em Economia Monetária e Financeira, Universidade Técnica de Lisboa.

"As opiniões expressas neste artigo não necessariamente representam as opiniões das instituições com as quais os autores mantém vínculos.
} 
agentes econômicos à obtenção de recursos, em prazos e volumes adequados, nos sistemas financeiros tradicionais (Hermann, 2005 e 2011; Paula, 2014; Montani Martins, 2012a: 102-107).

Neste sentido, embora o conceito de funcionalidade corresponda eminentemente a uma questão de grau ${ }^{1}$, os sistemas financeiros, em geral, podem ser caracterizados como disfuncionais a este grupo de agentes econômicos, que, contudo, representa uma engrenagem importante na estrutura econômica dos países, responsável pela geração de uma parcela significativa da renda e, principalmente, do emprego das economias.

O fenômeno do crowdfunding ou financiamento coletivo não é novo mas, recentemente, vem se difundido cada vez mais, assumindo uma vertente financeira, outrora desconhecida, e dando nova roupagem aos empréstimos e reunião de recursos de terceiros para o financiamento de projetos e negócios. Embora existam algumas definições distintas ${ }^{2}$, pode-se afirmar que o crowdfunding consiste numa forma alternativa de financiamento que conecta diretamente, por meio da internet $e$ das redes sociais $^{3}$, aqueles que podem ofertar, emprestar ou investir recursos com aqueles que necessitam de financiamento para projetos ou negócios específicos. Além disso, o financiamento coletivo é caracterizado pelo fato de que os projetos e negócios mencionados são financiados através de pequenas contribuições de um grande número de indivíduos, de forma anônima.

O crowdfunding vem crescendo constante e significativamente ao longo do tempo. De acordo com dados da Massolution (2013), as plataformas on-line dedicadas a viabilizar esse tipo de financiamento levantaram US\$2,66 bilhões do público ao redor do mundo em 2012, perante US\$ 0,89 bilhões em 2010 e R $\$ 1,47$ bilhões em 2011. A perspectiva é que este número atinja um patamar próximo a US\$ 5 bilhões em 2013.

Este crescimento exponencial merece também destaque quando comparado com a retração nos recursos fornecidos por outras fontes de financiamento, como o mercado de venture capital, desde a erupção da crise financeira internacional de 2008-9. Além disso, num ambiente onde novos e mais rigorosos requerimentos regulatórios reduzem - ao menos potencialmente - a disponibilidade de financiamentos e tornam-nos mais custosos aos tomadores, o crowdfunding ganha corpo como um instrumento alternativo para financiar projetos e negócios.

Em outras palavras, o crowdfunding pode: ajudar os agentes econômicos a acessar financiamentos de forma mais democrática; aumentar, potencialmente, a oferta de recursos disponíveis a financiar projetos e negócios; fornecer diferentes ativos aos investidores no momento

\footnotetext{
1 “O conceito de funcionalidade envolve duas dimensões fundamentais: (i) volume ou, em outras palavras, a utilização dos recursos; (ii) fragilidade financeira. [...] o conceito de funcionalidade de sistemas financeiros revela-se uma questão de grau e não uma medida absoluta, o que dificulta sua "mensuração" propriamente dita (e ainda mais sua comparação).” (Montani Martins, 2012b: 19).

${ }^{2}$ Ver a Seção 2.2.a. abaixo.

${ }^{3}$ Reconhecemos que formas similares de financiamento coletivo podem ocorrer através de outros canais, não digitais, mas não consideramos tais formas como relevantes para caracterizar o fenômeno aqui analisado.
} 
em que decidem sob que forma manter sua riqueza. Nesse contexto, o financiamento coletivo pode contribuir para a inclusão financeira e para ampliar o grau de funcionalidade dos sistemas financeiros ao desenvolvimento econômico.

Isto não significa, contudo, que esse instrumento somente gere benefícios. O crowdfunding também engendra riscos, que são tipicamente oriundos das relações e mercados financeiros. O financiamento coletivo, especialmente num ambiente como a internet, pode dar origem a inúmeras formas de fraude financeira e econômica. Plataformas on-line que intermediam os recursos do crowdfunding necessitam, então, de adotar diversos controles, procedimentos para evitar conflitos de interesse, verificação da precificação, técnicas de mitigação de risco e salvaguardas operacionais, especialmente no momento de eleger e selecionar projetos e negócios a serem financiados. Algumas obrigações de divulgação de informação e transparência são também desejáveis de modo a permitir o acompanhamento pelos contribuidores dos projetos financiados. Todavia, não há, um incentivo forte para que estas plataformas assim o façam, o que nos leva à uma situação em que o público ou os investidores - necessita de proteção às falhas tecnológicas, abuso de mercado e fraude.

Isso implica a necessidade de implementar ações regulatórias. É importante que as campanhas de financiamento - da mesma forma como outras ofertas públicas - sejam reguladas pelas autoridades, assim como as plataformas que fornecem os serviços relacionados ao crowdfunding. Regras de proteção aos clientes/investidores são também necessárias para fornecer a proteção adequada ao público. Como destacado por De Buysereet al. (2012: 33), a regulação é crítica para a "indústria" do crowdfunding e deve abordar diferentes categorias: "operational and financial transparency, security of information and payments, platformf unctionality, customer protection, and operational procedures". Com essa perspectiva, fica claro que o crowdfunding engendra diversos desafios regulatórios que dependem das respostas das autoridades ao redor do mundo ${ }^{4}$.

O presente artigo tem como objetivo analisar a relação entre a funcionalidade do sistema financeiro e o financiamento coletivo através da internet. Mais especificamente, ele tem interesse em avaliar quais as questões regulatórias relevantes para que o crowdfunding possa auxiliar efetivamente os agentes e ampliar a funcionalidade das finanças ao desenvolvimento econômico.

Ele está dividido em quatro seções, sendo a primeira esta introdução. A Seção 2 discute a relação entre o crowdfunding e a inclusão financeira, destacando o papel que esta forma de financiamento pode desempenhar na ampliação da funcionalidade dos sistemas financeiros, amplamente falando, para o desenvolvimento econômico. A terceira Seção analisa os desafios

\footnotetext{
${ }^{4}$ Com efeito, o crowdfunding tem dimensão global, pelo simples fato de atuar na rede mundial de computadores e estar disponível além fronteiras a qualquer investidor; também por isso, portanto, requer particular atenção das autoridades competentes ao redor do mundo.
} 
regulatórios engendrados pelo crowdfunding e adianta algumas respostas já oferecidas por reguladores da Itália, França, Alemanha, Reino Unido e Estados Unidos. A quarta e última seção conclui o artigo e tece algumas considerações sobre o Brasil, ressaltando a importância de definir uma agenda de pesquisa sobre o tema no país.

\section{Crowdfunding e a ampliação da funcionalidade dos sistemas financeiros para o desenvolvimento econômico}

\subsection{Base teórica: da eficiência à funcionalidade dos sistemas financeiros}

A teoria econômica moderna superou as controvérsias acerca da relação entre os sistemas financeiros e o crescimento econômico (Levine, 2004: 1): atualmente, pode-se afirmar com segurança que os sistemas financeiros desempenham um papel relevante na promoção do crescimento econômico e no desenvolvimento econômico ${ }^{5}$.

Mais especificamente, as instituições e intermediários financeiros são responsáveis pela criação e pela alocação de moeda, tornando os recursos disponíveis para financiar os planos de consumo e investimentos dos agentes econômicos. Estas entidades também fornecem serviços ao público em geral, operando sistemas de pagamento, fornecendo conselhos sobre a alocação da riqueza em ativos financeiros, estruturando emissões de papéis das empresas, dentre outras inúmeras atividades.

A economia neoclássica usualmente emprega o termo eficiência para analisar a capacidade que um sistema financeiro possui de influenciar positivamente o crescimento econômico, através da melhor alocação de recursos entre poupadores e tomadores ou, respectivamente, unidades financeiras superavitárias e deficitárias, de acordo com a terminologia de Gurley e Shaw (1955). Na construção teórica neoclássica o sistema financeiro opera eminentemente na função de intermediário (Paula, 2014) e os preços dos ativos financeiros espelham plena e corretamente toda a informação relevante disponível sobre o curso futuro dos mercados, tal como estabelecido na hipótese dos mercados eficientes (HME) (Malkiel, 1992) ${ }^{6}$.

Shaw (1973) e McKinnon (1973) destacam duas principais funções do sistema financeiro "neoclássico": (i) oferecer ativos que remunerem adequadamente as unidades superavitárias, de acordo com suas preferências; com isso, as instituições financeiras também captariam a poupança necessária para (ii) ofertar apropriadamente recursos às unidades deficitárias, de modo a alavancar o potencial de investimento destas.

\footnotetext{
${ }^{5}$ De modo simplificado, pode-se entender desenvolvimento econômico como crescimento econômico com mudança estrutural (Furtado, 1967; Schumpeter, 2008).

${ }^{6}$ Ver também Fama (1970).
} 
Considerando a HME como uma hipótese válida, pode-se assumir que os preços dos ativos financeiros refletem corretamente a informação disponível e, assim, determinam a capacidade do sistema financeiro atrair recursos do público e elevar o nível de poupança agregada. Destarte através da alocação ótima desses recursos entre as unidades que os necessitam os investimentos seriam alavancados, assim como o crescimento econômico.

Além disso, como sintetizado por Studart (1995-96: 269), a liberalização dos sistemas financeiros ${ }^{7}$ é diretamente associada à eficiência do mesmo na alocação de capital:

"Efficiency is thus clearly associated with a more liberalized, deregulated financial system. This argument, in turn, is implicitly based on the dominant view on the working of financial markets that is, that financial institutions can be pictured as mere intermediaries between savers and investors. Further, the argument also relies on the view that the prices of financial assets reflect the underlying conditions of the final issuers of such assets, a view that has more recently been formalized as the efficient market hypothesis. If financial markets are the loci of allocation of capital, and asset prices are shown to guide savers toward investment with the highest productivity, financial markets are efficient allocators of capital."

A eficiência dos sistemas financeiros - assim como o próprio processo de liberalização financeira - pregada pela economia neoclássica, entretanto, pode ser diretamente questionada, em função da desmontagem das hipóteses básicas que a sustentam como resultado, bem como da própria redefinição do papel do sistema financeiro em economias com características diferentes. A crítica às hipóteses básicas pode ser resumida, basicamente, pelo argumento de Stiglitz (1989: 61):

"much of the simplistic advice given by 'Chicago' economists is based on the hypotheses that markets for capital are just like markets for chairs and tables; that free markets - whether for chairs, tables, or capital - ensure Pareto efficient resource allocations; and that policies that move the economy closer to free market solutions are welfare enhancing. All three of these presumptions are incorrect."

Desta crítica, Stiglitz (1989; 1994), bem como outros autores que se encaixam na corrente Novo-Keynesiana, passam a reconhecer a existência de falhas de mercado, o que torna a alocação provida puramente pelos sistemas (mercados) financeiros ineficiente. Notadamente, como sintetiza Hermann (2011: 7), a presença de "a) custos de transação; b) custos e assimetria de informação; c) externalidades positivas e negativas; d) mercados incompletos; e) concorrência imperfeita" gera uma posição de equilíbrio subótimo, ineficiente no sentido de Pareto. Ainda que os fatores (d) e (e) possam ser enxergados como circunstanciais, os fatores de (a) a (c) são característicos das economias, o que torna esta condição de ineficiência sistemática.

Igual crítica é compartilhada por autores pós-Keynesianos, porém de forma ainda mais visceral. Sinteticamente, no contexto de uma economia monetária de produção onde vigorem

\footnotetext{
${ }^{7}$ Hermann (2002: 42) argumenta que as teorias de liberalização financeira de Shaw e McKinnon têm como base as teorias do crescimento exógeno, que estabelecem que a taxa de crescimento de longo prazo é positivamente relacionada e determinada pela taxa de poupança agregada. Ver também Snowdown e Vane (2005: 598-602).
} 
condições de incerteza, o mercado é sistematicamente ineficiente - o que possui sua tradução macroeconômica no fato de que os agentes preferem liquidez e que o sistema é permanentemente sujeito a crises financeiras. Ainda, o próprio conceito de eficiência macroeconômica perde sentido num ambiente cerceado pela incerteza. Isto tudo gera um "pessimismo" pós-Keynesiano em relação à possibilidade de que sistemas financeiros, por si só, operem em permanente apoio ao desenvolvimento econômico. Mais que isso, tal característica gera também uma redefinição do próprio papel desempenhado pelos sistemas financeiros em economias monetárias de produção.

O papel dos sistemas financeiros para a teoria pós-Keynesiana está ligado diretamente a dois elementos: o estabelecimento de um sistema de contratos (monetários) que coordene a atividade econômica num contexto de incerteza; a provisão de finance e funding apropriados para a demanda efetiva, que a sustente no longo prazo.

Os contratos monetários estabelecidos entre os agentes envolvem a promessa de pagamentos em moeda no futuro, ou, como denomina Minsky (1992: 2), "[the] exchange of present money for future money", de modo a mitigar ou mesmo eliminar a incerteza envolvida a algumas operações. Cada contrato representa uma obrigação assumida, de um lado, e um ativo retido, de outro. Cada agente ou unidade econômica possui, assim, uma espécie de balanço, que reúne seus ativos e passivos, ou promessas de recebimento ou pagamento no futuro - além das posições no presente (Minsky, 1960: 184). Estes contratos são contratos financeiros por definição e constituem a base das relações financeiras.

Desse modo, pode-se afirmar que as relações financeiras que caracterizam as economias monetárias de produção são construídas sobre este sistema de contratos monetários. Neste meio, emergem as instituições financeiras. Como Minsky (1960: 187) destaca:

"Financial institutions are typically business organizations which own financial assets and emit financial liabilities. This interposition by financial institutions takes various forms among which are the endorsing of other's liabilities, the emission of their own liabilities in order to finance a position in other's liabilities, and pure "brokerage" activities, which make markets. [...] Financial intermediaries which endorse, make otherwise unacceptable liabilities acceptable because of their expert evaluation and their net worth."

A capacidade que os intermediários financeiros - em especial, os bancos - possuem em criar obrigações ganha caráter especial quando estas obrigações passam a ser percebidas pelo público como moeda. Como coloca Minsky (1960: 190), “[m]oney is that which can be used, by its owner, in its present form to make payments." Assim, a partir do momento em que os bancos assumem a condução do sistema de pagamentos da economia - com o respaldo do Estado - não apenas a transformação de liquidez lhes é própria, mas também a possibilidade de criar moeda.

Isso fica claro quando remontamos à discussão sobre o financiamento do investimento e a provisão de finance e funding. Ao fornecer o finance necessário aos investimentos, os bancos criam 
uma espécie de fundo rotativo, que nada mais é que uma operação contábil, exatamente nos termos empregados nos parágrafos anteriores. Como destacado por Keynes (1937a), a relevância dos bancos para a viabilização do investimento é soberana. Soma-se a isso o complemento fornecido pelos demais intermediários financeiros (que não operam o sistema de pagamentos diretamente) e os mercados de capitais, por meio da promoção do alinhamento entre as condições de demanda e oferta de ativos financeiros, desenvolvendo, portanto, contratos que garantissem que o funding dos investimentos possa ser concretizado ${ }^{8}$.

Em outros termos, o sistema financeiro tem por papel central a criação e canalização de recursos da circulação financeira para a circulação industrial (isto é, do mercado de ativos para o mercado de bens e serviços $)^{9}$ para dar sustento ao processo produtivo e, sobretudo, o processo de investimento.

A rationale para instituições financeiras - em especial, os bancos - adiantarem recursos às empresas (e mesmo às demais instituições financeiras) é a busca de lucros monetários, a partir das promessas de renda futura que estas realizam a favor daquelas, como contrapartida. Numa economia monetária de produção,

"a atividade econômica e as relações financeiras que a viabilizam, derivam e dependem, para sua sustentação, de um 'sistema de confiança'. Este envolve, de um lado, as expectativas de renda futura daqueles que assumem dívidas (os investidores finais) e, de outro, as expectativas de retorno-risco daqueles que adquirem os ativos financeiros criados no processo de produção e investimento (poupadores finais e instituições financeiras).” (Hermann, 2002: 193)

Quando estabelecidos os contratos ou obrigações, refletem a percepção corrente acerca do ambiente econômico e das variáveis relevantes para a operação em particular. Em outras palavras, "[f]inancing practices result in payment commitments that are embodied in contracts that reflect market conditions and expectations that ruled when they were negotiated and signed" (Minsky, 1986: 219).

Em fases de otimismo, estabilidade e crescimento, os agentes tenderiam a incorrer em investimentos e aplicar em ativos mais arriscados e cujo retorno é mais incerto, tanto voluntariamente, em função de seu otimismo exacerbado, como involuntariamente, em função de possíveis subestimações dos reais riscos aos quais estão se expondo. Neste processo, o nível de endividamento (ou a expansão das obrigações) do sistema como um todo se ampliaria - espaço onde os sistemas financeiros ocupam posição central.

O que marca igualmente este processo é que o objetivo final das instituições financeiras é a busca por lucros monetários. Isto confere papel especial às inovações financeiras e aos instrumentos

\footnotetext{
${ }^{8}$ Sobre a dinâmica de finance e funding, ver Keynes (1937a e 1937b).

${ }^{9}$ Keynes (1929).
} 
utilizados, como elementos dinâmicos dentro desta lógica. A possibilidade de subestimação de riscos em fases de otimismo seriam características igualmente válidas para o sistema financeiro.

A conjunção destes modi operandi num contexto de incerteza acaba por criar uma tendência inerente à fragilização das posições financeiras nesta economia. Esta é justamente a hipótese de instabilidade financeira (HIF) levantada por Minsky (1992). Ou seja, o que a HIF sublinha é que à medida que um quadro de otimismo, estabilidade e crescimento se mantenha, posições cada vez mais frágeis do ponto de vista financeiro tendem a ser geradas, o que, em última instância, pode gerar um colapso do sistema econômico como um todo, iniciado a partir do setor financeiro. Em outras palavras, a HIF definida por Minsky (1982: 67-8 apud Hermann, 2002: 192) constitui uma teoria de "how a capitalist economy endogenously generates a financial structure which is susceptible to financial crises, and how the normal functioning of financial markets in the resulting boom economy will trigger a financial crisis."

Nesse contexto, pode-se afirmar que a incerteza a qual permeia as economias monetárias de produção gera uma condição sistemática de ineficiência dos mercados financeiros. A preferência pela liquidez e a hipótese de fragilidade financeira traduzem dois "canais" fundamentais pelos quais esta ineficiência se manifesta. Nesse contexto, o que fica claro é que: "os recursos desenvolvidos para [contornar a incerteza] têm eficácia limitada, o que mantém a condição de ineficiência do mercado, mesmo no plano microeconômico.” (Hermann, 2011: 10).

Mais que isso, deve-se considerar que no contexto de incerteza as expectativas e o grau de confiança de cada agente não são necessariamente iguais, mesmo que todos utilizem o mesmo conjunto de informação disponível no presente. O conjunto total de informações, por assim dizer, depende do julgamento sobre o futuro de cada um - o que pode diferir substancialmente. Neste contexto, o que pode ser "eficiente" para um agente pode ser "ineficiente" para outro, fazendo com que o próprio conceito de eficiência torne-se irrelevante ao considerarmos o agregado do mercado financeiro, isto é, o plano macroeconômico.

Isso não significa, contudo, que a preferência pela liquidez e a hipótese de instabilidade financeira fadam as economias monetárias de produção necessariamente a um colapso. Existe, sim, a possibilidade inerente de crises financeiras ocorrerem. Contudo, esta possibilidade depende do caráter que a expansão e desenvolvimento do sistema financeiro e as posições tomadas pelos agentes assumam.

Para determinados autores pós-Keynesianos, pode-se conviver com uma expansão do grau de fragilidade que se revele "sustentável". O conceito de funcionalidade do sistema financeiro, definido por Studart (1995: 64), surge neste contexto. Como o autor apresenta:

"a financial system is functional to the process of economic development when it expands the use of existing resources in the process of economic development with 
the minimum possible increase in financial fragility and other imbalances, that may halt the process of growth for purely financial reasons."

$\mathrm{Na}$ perspectiva pós-Keynesiana, pensar desenvolvimento financeiro sem integrá-lo ao conceito de funcionalidade para o desenvolvimento econômico implica um pessimismo exacerbado sobre o papel que o sistema financeiro pode exercer no desenvolvimento econômico.Partindo da perspectiva de Carvalho (2010: 9), pode-se redefinir o conceito de funcionalidade de modo que chamemos atenção a um aspecto específico:

"Um sistema financeiro funcional no apoio ao desenvolvimento econômico tem de cumprir duas funções essenciais: disponibilizar recursos financeiros para a sustentação do processo produtivo e da realização de investimentos [...] no volume e nos termos apropriados; e criar ativos financeiros com os perfis de retorno e risco demandados pelos agentes privados para que estes possam acumular riqueza."

Nesta definição, o desenvolvimento financeiro seria compatível com o desenvolvimento econômico sustentado, em especial, se for capaz de criar instrumentos e estruturas financeiras que provisionem o funding adequado das posições dos agentes - especificamente, dos investimentos. Com o funding adequado, os descasamentos das posições financeiras dos agentes seriam igualmente limitados, o que diluiria a fragilidade financeira ao longo do processo de desenvolvimento.

\subsection{Crowdfunding como um instrumento alternativo de financiamento}

A probabilidade que os mercados financeiros privados desenvolvam por si instrumentos e estruturas que permitam um adequado balanço entre a disponibilização dos recursos e a fragilidade financeira sistêmica é pequena, dadas as características que definem a operação deste mercado, o que justifica o "pessimismo" pós-Keynesiano.

Em especial, o diagnóstico aponta para os seguintes problemas a serem tratados: (i) a instabilidade financeira característica de economias monetárias de produção; (ii) a preferência pela liquidez, que limita a demanda por ativos a determinada classe de ativos financeiros, atrofiando também o desenvolvimento de alguns segmentos do mercados financeiros; (iii) a dificuldade de acesso aos mercados financeiros por determinados agentes.

Em relação a estes dois últimos elementos, MINDS (2012: 10, grifos meus) aponta que setores- e agentes-chave para o desenvolvimento econômico se encontram dentro do conjunto de (ii) e (iii), em especial, manifesta-se uma atrofia ou subdesenvolvimento nos seguintes segmentos de tomadores ou do mercado financeiro:

"a) in the capital markets, [as] the result of high risk posed to non-professional investors;

b) in long-term credit in general, whose risks are more difficult to evaluate over the long terms involved;

c) in credit offered to small and medium-sized companies, to which, because of their lower volume of revenues and more limited guarantees, the market tends to attribute a higher credit risk than that attributed to larger companies; 
d) in the financing of $R \& D$ and innovation in general, which offers a combination of difficulties associated with the very novelty of the product (or of the productive process), which makes it difficult to assess the probability of success of the endeavor; the term to maturity of the investment (difficult to forecast); the level of acceptance of the new product in its market, etc."

De fato, prevalecendo as condições de incerteza inerentes às economias monetárias de produção, os ativos de agentes de tamanho restrito tendem a apresentar menor liquidez e a provisão de crédito para os mesmos responde à características específicas de seu padrão de negócios:

"Startups and small businesses usually have smaller and more variable cash flows than larger more established companies, and internal financing from their own business operations tends to be limited and unstable. Moreover, these businesses tend to have smaller asset bases and, thus, less collateral for traditional bank loans." (SEC, 2013: 346).

Sob uma perspectiva menos teórica, a Comissão Europeia (2011: 1) reconhece que "SMEs often face significant difficulties in obtaining the financing they need in order to grow and innovate”. Da mesma forma, Belleflame et. al (2013: 4) destacam:

"It is well recognized that new firms face difficulties in attracting external finance during their initial stage, be it through bank loans or equity capital [...]. Many entrepreneurial ventures remain unfunded, partly because of a lack of sufficient value that can be pledged to financial investors and partly because of unsuccessful attempts to convince investors".

Disso se conclui que o restrito acesso das pequenas e médias empresas e empreendedores (PMEEs) aos recursos do sistema financeiro privado tradicional é uma condição perene de ineficiência do mesmo ou, embora, como já destacado, o conceito de funcionalidade seja uma questão de grau, os sistemas financeiros podem ser caracterizados como disfuncionais a este grupo de agentes econômicos, que, contudo, tem peso relevante nas economias, sendo responsável pela geração de uma parcela significativa da renda e, principalmente, do emprego das economias.

Se o sistema financeiro tradicional não é capaz de prover, regularmente, recursos nos volumes e custos adequados para pequenas e médias empresas, formas alternativas de financiamento, à margem das instituições financeiras tradicionais, podem ser empregadas para tal propósito. O microcrédito, por exemplo, pode ser considerado uma dessas alternativas, tendo sido amplamente discutido e analisado em diversos países, inclusive no Brasil (Yunus, 2003; Neri e Medrado, 2005; Hermann, 2005; Neri, 2008; Montani Martins, 2012a: Capítulo V). Mais recentemente, como colocado na introdução deste artigo, o fenômeno do crowdfunding ou financiamento coletivo tem se difundido cada vez mais, dando nova roupagem aos empréstimos e reunião de recursos de terceiros para o financiamento de projetos e negócios. 


\section{2.a. Crowdfunding: uma proposta de conceituação}

Emprestar ou reunir recursos do público para o financiamento de projetos e atividades econômicas são ações corriqueiras, que tomam lugar nos mercados financeiro e de capitais tradicionais. Essas ações estão na origem destes mercados, que hoje constituem uma complexa e profunda rede de relações financeiras, formalmente estabelecidas e amparadas por arcabouços regulatórios dedicados. Mais recente, contudo, é a utilização da Internet e das redes sociais para promover esse tipo de arranjo e essas relações, sem contar com o formalismo característico das relações financeiras tradicionais.

Embora a utilização da Internet seja um fenômeno relativamente novo, que vem ganhando peso, especialmente, a partir dos anos 2000, há que se destacar que práticas similares ao crowdfunding vêm sendo empregadas há tempos - o que reflete que a dificuldade de acesso ao sistema financeiro para angariar recursos não é uma característica nova, mas perene do sistema, reforçando a crítica à abordagem neoclássica. Segundo Hemer (2011: 1):

"Mozart e Beethoven financiaram concertos e publicações de novas partituras através de adiantamentos de partes interessadas. A Estátua da Liberdade em Nova Iorque foi financiada por pequenas doações de americanos e franceses. Em 1997, a banda de rock britânica Marillion coletou US\$ 60 mil de seus fãs através de uma chamada na Internet para financiar sua turnê nos EUA.”

A falta de ineditismo nas práticas caras ao financiamento coletivo acabam por criar uma situação onde a conceituação do fenômeno mais recente não é consensual. De Buysere et al. (2012: 9, grifos meus) propõe que:

"Crowdfunding can be defined as a collective effort of many individuals who network and pool their resources to support efforts initiated by other people or organizations. This is usually done via or with the help of the Internet. Individual projects and businesses are financed with small contributions from a large number of individuals, allowing innovators, entrepreneurs and business owners to utilize their social networks to raise capital."

O esforço coletivo de uma larga massa de indivíduos ${ }^{10}$, através de pequenas contribuições individuais, é, com efeito, uma característica marcante do crowdfunding, dissolvendo e limitando a participação de cada agente no financiamento do projeto ou negócio em questão - diferentemente, por exemplo, de um empréstimo bancário, forma usualmente mais acessível para o financiamento de pequenas e médias empresas, onde dois únicos agentes participam do processo, o banco e a empresa.

\footnotetext{
${ }^{10}$ A grande inovação que a Internet possibilitou aos financiamentos coletivos é justamente a dimensão global e o acesso a um sem número de contribuidores que possibilita que os financiamentos sejam realizados através de pequenos investimentos de muitos indivíduos. Isso os permite encarar de uma forma menos avessa ao risco projetos que são de alto risco (start-ups) e que, em qualquer outra circunstância - especialmente através dos mecanismos tradicionais fornecidos pelos sistemas financeiros (por exemplo, um fundo de venture capital), nunca estariam dispostos a financiar.
} 
A utilização da Internet, para os autores, é uma possibilidade, mas não condiciona a prática. Para a Comissão Europeia (2013: 2), entretanto, este pode ser considerado um elemento fundamental:

"crowdfunding is an emerging alternative form of financing that connects directly those who can give, lend or invest money with those who need financing for a specific project. While calls for funds to the public are not new, the phenomenon of using the internet to directly connect with funders emerged recently."

Tal perspectiva é reforçada pela IOSCO (2014: 8), que define crowdfunding como "an umbrella term describing the use of small amounts of money, obtained from a large number of individuals or organizations, to fund a project, a business or personal loan, and other needs through an online web-based platform". Isto é, para a IOSCO, a utilização da Internet é uma característica fundamental. O mesmo vale para a FCA (2013: 4): "Crowdfunding is a way in which people, organizations and businesses (including business startups) can raise money through online portals (crowdfunding platforms) to finance or re-finance their activities and enterprises".

A combinação das duas características mencionadas acima, dispersão e uso da Internet, é também mencionada na definição utilizada pela SEC (2013: 1):

"Crowdfunding is a term used to describe an evolving method of raising money through the Internet. For several years, this funding method has been used to generate financial support for such things as artistic endeavors like films and music recordings, typically through small individual contributions from a large number of people."

Outros autores identificam o crowdfunding com definições mais específicas. Por exemplo, Lambert e Schwienbacher (2010: 8), definem que:

"Crowdfunding involves an open call, essentially through the Internet, for the provision of financial resources either in form of donations (without rewards) or in exchange for some form of reward and/or voting rights in order to support initiatives for specific purposes"

Hemer (2011: 8), segue a mesma linha dos autores anteriores, identificando o termo crowdfunding a outro termo relacionado à reunião de recursos do público, o crowdsourcing, porém destacando o anonimato como uma característica do processo:

"The term 'crowdfunding' is derived from the better known term 'crowdsourcing', which describes the process of outsourcing tasks to a large, often anonymous number of individuals, a 'crowd of people' (here: the Internet community) and drawing on their as-sets, resources, knowledge or expertise. In the case of crowdfunding, the objective is to obtain money."

Destas discussões, pode-se depreender um conceito que reúna todas as características mencionadas pelos autores acima:o crowdfunding ou financiamento coletivo conecta diretamente, por meio da Internet e das mídias sociais, as pessoas que podem doar, emprestar ou investir dinheiro com aquelas que necessitam deste dinheiro para financiar um projeto ou negócio que 
desejam realizar, através de pequenas contribuições de um grande número de indivíduos, que juntos, de forma anônima, formam a massa crítica para viabilizá-los.

Nesse conceito, quatro elementos são fundamentais: a utilização da Internet, notadamente, de plataformas on-line dedicadas à viabilização do financiamento e das redes sociais para divulgação das campanhas; a dispersão ou fragmentação das contribuições (empréstimos, aplicações ou investimentos) num coletivo de agentes (the crowd); o anonimato inerente a essas contribuições; e a decorrente informalidade dessas relações "financeiras".

Cabe destacar que as relações estabelecidas entre os contribuidores e os projetos/negócios de crowdfunding não são, em geral, estritamente financeiras e respondem também a motivações emocionais - identificação pessoal com o projeto/negócio -, geográficas - identificação pessoal com uma região específica -, sociais - com caráter de caridade - ou mesmo materiais - relativas ao desejo de receber um produto/serviço. Neste sentido, é importante destacar que nem todas as formas de crowdfunding se assemelham aos instrumentos financeiros tradicionais: por exemplo, diversas campanhas visam viabilizar o lançamento de discos musicais ou constituem no pagamento antecipado por um produto que será desenvolvido. Todavia, algumas formas são substitutas quaseperfeitas dos instrumentos financeiros tradicionais, como os empréstimos aos pares (peer-to-peer lending) e a troca de participações dos projetos ou negócios (equity crowdfunding).

A Tabela 1 abaixo descreve as diferentes formas que pode tomar o crowdfunding e as principais características de cada uma delas. 


\section{Tabela 1: Diferentes Tipos de Crowdfunding}

\begin{tabular}{|c|c|c|}
\hline Tipo & Características & $\begin{array}{l}\text { Principal } \\
\text { Interesse }\end{array}$ \\
\hline Doações & $\begin{array}{l}\text { Pessoas fornecem recursos para a realização de um determinado } \\
\text { projeto/negócio, sem que nada seja prometido em retorno. }\end{array}$ & Social \\
\hline Recompensas & $\begin{array}{l}\text { Produtos/serviços, tipicamente de baixo valor material e baixo valor } \\
\text { em relação ao da contribuição, são ofertados como contrapartida às } \\
\text { contribuições. }\end{array}$ & Material \\
\hline Pré-vendas & $\begin{array}{l}\text { As campanhas visam vender adiantadamente um novo } \\
\text { produto/serviço ou adiantar recursos para o desenvolvimento de um } \\
\text { novo produto/serviço, oferecendo-o em troca das contribuições. }\end{array}$ & Material \\
\hline Empréstimo Social & $\begin{array}{l}\text { Há a possibilidade de realizar empréstimos a juros nulos para } \\
\text { projetos, comumente de cunho social, por determinado prazo e } \\
\text { depois receber os recursos de volta. }\end{array}$ & Social \\
\hline $\begin{array}{l}\text { Empréstimos/ } \\
\text { Empréstimos aos } \\
\text { pares }\end{array}$ & $\begin{array}{l}\text { Um empreendedor ou uma pequena empresa, ao invés de recorrer a } \\
\text { um banco ou similar, contrai um empréstimo, pactuando o } \\
\text { pagamento de juros e principal, junto ao coletivo de contribuidores, } \\
\text { que assumem a posição de credores. }\end{array}$ & Financeiro \\
\hline Dívida & $\begin{array}{l}\text { Um empreendedor ou uma pequena empresa contrai uma dívida } \\
\text { junto aos contribuidores, que assumem a posição de credores. }\end{array}$ & Financeiro \\
\hline Divisão dos lucros & $\begin{array}{l}\text { Estabelecem-se arranjos de repartição dos lucros futuros entre os } \\
\text { contribuidores e os empreendedores/empresas. }\end{array}$ & Financeiro \\
\hline Participações & $\begin{array}{l}\text { A campanha oferece a participação no negócio/projeto através da } \\
\text { compra de uma parcela da titularidade do mesmo, tal como no caso } \\
\text { de uma ação. Ao invés de recorrer a investidores anjos ou fundos de } \\
\text { venture capital, o empreendedor ou a empresa busca investidores } \\
\text { no coletivo de pessoas. }\end{array}$ & Financeiro \\
\hline Híbridos & $\begin{array}{l}\text { Mesclam formas distintas onde o interesse financeiro é } \\
\text { predominante ou formas financeiras com outras onde o interesse } \\
\text { social/material é mais importante (e.g., empréstimos com pré- } \\
\text { venda). }\end{array}$ & Diversos \\
\hline
\end{tabular}

Fonte: Elaboração própria a partir de DeBuysere et al. (2012: 10-11) e Comissão Europeia (2013).

De interesse científico, deve-se destacar, são as formas orientadas pelo interesse financeiro, que fazem da prática do crowdfunding um instrumento de captação dos agentes - em especial, empreendedores individuais e pequenas e médias empresas -, criando, portanto, um mercado paralelo de recursos, alternativo ao sistema financeiro tradicional. Como ressalvado pela IOSCO (2014: 10):

"FR [Financial Return] crowd-funding is a new innovation of market based finance. Due to technological advancements making these markets viable, FR crowd-funding is solely an internet based market. In addition, the ability to allow many investors to invest small amounts of an overall funding request means it is accessible to a vast number of potential investors and borrowers. Not only this, but in the case of peerto-peer lending it is open to many different types of investors, with varying capacities and risk appetites. This makes this industry different from private placement or other similar activities."

Cabe, entretanto, qualificar o argumento da IOSCO: o crowdfunding é uma inovação financeira que não está restrita ao mercado de capitais, mas se estende também ao mercado de crédito, porém de uma forma descentralizada dos bancos tradicionais. 


\section{2.b. Crowdfunding e a funcionalidade do sistema financeiro para o desenvolvimento econômico}

Considerando o conceito de funcionalidade do sistema financeiro explorado na seção anterior, é notável a capacidade que o crowdfunding tem em prover atendimento a segmentos excluídos e/ou restringidos no sistema financeiro privado tradicional, ampliando o acesso dos empreendedores individuais e/ou pequenas e médias empresas aos recursos financeiros. Da mesma forma, tal instrumento permite uma maior disponibilização de recursos para a realização de investimentos, sob a forma de projetos específicos, em volumes e termos mais favoráveis que o sistema financeiro tradicional.

Do ponto de vista dos investidores, por assim dizer, destacamos que as relações estabelecidas entre os mesmos e os projetos e/ou negócios não são única e exclusivamente financeiras, respondendo igualmente a motivações emocionais, geográficas, sociais e/ou materiais. Tal característica permite dissociar do projeto a mera e fria análise financeira do mesmo, compensando a incerteza relativa às condições de viabilidade financeira dos projetos/negócios pelas motivações pessoais de cada contribuidor. Esse fato contribui para que o ativo em que ele invista esteja adequado não pura e simplesmente ao perfil de retorno e risco por ele demandado, mas aos seus anseios, de modo geral.

Estes papéis se colocam não só do ponto de vista teórico, mas também na realidade prática. Como reconhecido em Relatório da Comissão Parlamentar em Padrões Bancários do Legislativo britânico, intitulado Mudando os Bancos para Melhor:

"Peer-to-peer and crowdfunding platforms have the potential to improve the UK
retail banking market as both a source of competition to mainstream banks as well
as an alternative to them. Furthermore, it could bring important consumer benefits
by increasing the range of asset classes to which consumers have access. This access
should not be restricted to high net worth individuals but, subject to consumer
protections, should be available to all. The emergence of such firms could increase
competition and choice for lenders, borrowers, consumers and investors." (House of
Commons, 2013: 220 , grifos meus).

Isto é, segundo a visão do Parlamento britânico, além de fornecer uma alternativa ao sistema bancário tradicional, o crowdfunding pode beneficiar os agentes através da criação de pressões competitivas ao sistema privado regular ${ }^{11}$.

A Comissão Europeia (2014: 2-3), por sua vez, explora o papel de complementaridade que o financiamento coletivo pode exercer na região. Em especial, num ambiente onde novos e mais rigorosos requerimentos regulatórios reduzem - ao menos potencialmente - a disponibilidade de

\footnotetext{
${ }^{11}$ Estas pressões existem, também, pelo fato de que no crowdfunding quem demanda os recursos solicita efetivamente o que necessita sob pena de não conseguir ter o sucesso desejado no espaço de tempo pré-fixado junto dos emprestadores. Como as campanhas de promoção são curtas e mais eficazes nos extremos temporais (lançamento e encerramento,) valores desajustados dos projetos podem desencorajar os contribuidores de investir e comprometer o sucesso da captação de fundos.
} 
financiamentos e tornam-nos mais custosos aos tomadores, o crowdfunding ganha corpo como um instrumento alternativo para financiar projetos e negócios:

"O financiamento coletivo poderá contribuir muito para complementar as fontes tradicionais de financiamento e para o financiamento da economia real. O Livro Verde sobre o financiamento a longo prazo da economia europeia lançou um amplo debate sobre os diferentes fatores que permitem à economia europeia canalizar fundos para os investimentos a longo prazo necessários para garantir o crescimento econômico. [...]O financiamento coletivo consta desse plano de trabalho. Representa um novo modelo de financiamento, que contribui cada vez mais para ajudar as empresas em fase de arranque a subir a 'escada rolante do financiamento' e para a construção de uma economia de mercado social pluralista e com maior capacidade de resistência. O financiamento coletivo tem reais potencialidades para diferentes tipos de projetos, nomeadamente projetos inovadores, criativos e culturais, ou para as atividades dos empresários sociais, que têm dificuldades em aceder a outras formas de financiamento."

De forma mais holística, a IOSCO (2014: 21-22) sistematiza os benefícios do instrumento sob diferentes aspectos: (a) ajudar o crescimento econômico através do direcionamento de fluxos crescentes de recursos para pequenas e médias empresas e outros usos na economia real; (b) preencher uma lacuna deixada pelos bancos; (c) diminuir o custo do capital, se alavancando em cima de uma estrutura de baixo custo; (d) fornecer um novo produto que permita maior diversificação de portfólio dos investidores; (e) a eficiência de custos das plataformas on-line; (f) a conveniência do instrumento para os investidores; e (g) o aumento da competição ${ }^{12}$.

Com efeito, mais de US\$ 2,5 bilhões foram captados através de plataformas de crowdfunding em 2012 e a expectativa é que este valor dobre e alcance cerca de US\$ 5 bilhões em 2013 - o salto é ainda mais significativo quando comparado a 2010, quando o valor obtido foi US\$ 0,9 bilhão. Filtrando estes dados para os tipos exclusivamente financeiros de crowdfunding, a IOSCO (2014: 4) estima que o mercado de financiamento coletivo superou as cifras de US\$ 1 bilhão nos Estados Unidos, Reino Unido e China em 2013 e que existiam mais de US\$ 6,4 bilhões de estoque de empréstimos aos pares ao redor do mundo no final do mesmo ano.

Vale resgatar que o crescimento exponencial do crowdfunding ocorre na contramão dos mercados tradicionais, que convivem, desde a crise, com uma situação de escassez na oferta de recursos, também por motivos regulatórios, especialmente para agentes de menor representatividade econômica- sobretudo, na Europa. Fica claro, portanto, o caráter complementar, em relação ao sistema financeiro tradicional, que esse segmento possui - de fato, dificilmente o modelo de crowdfunding será viável para o financiamento de largas somas ou para projetos e negócios em estágios avançados de desenvolvimento, sendo muito mais direcionado a projetos menores e agentes de tamanho restrito.

\footnotetext{
${ }^{12}$ Além disso, embora não haja evidência empírica que suporte tal afirmativa, o financiamento coletivo tem potencial de atrair novos investidores para o mercado de capitais, que pelas restrições de liquidez que enfrentam não seriam investidores dos ditos produtos tradicionais.
} 
Em síntese, o crowdfunding pode: ajudar os agentes econômicos a acessar financiamentos de forma mais democrática; aumentar, potencialmente, a oferta de recursos disponíveis a financiar projetos e negócios; fornecer diferentes ativos aos investidores no momento em que decidem sob que forma manter sua riqueza. Nesse contexto, o financiamento coletivo pode contribuir para a inclusão financeira e para ampliar o grau de funcionalidade dos sistemas financeiros ao desenvolvimento econômico.

\section{Os desafios regulatórios do crowdfunding}

É importante resgatar que o conceito de funcionalidade não está dissociado do conceito de fragilidade financeira e que, assim, os riscos associados a um mercado ou instrumento específico estão também no cerne da determinação de sua funcionalidade para o desenvolvimento econômico. Neste sentido, para garantir que o crowdfunding se torne um instrumento efetivo de viabilização de financiamentos para PMEEs é necessário avaliar quais riscos tal veículo pode engendrar e quais as formas de mitigá-los, de modo a não comprometer o grau de fragilidade financeira de cada agente e, em última instância, do sistema como um todo.

\subsection{A relação entre crowdfunding e risco}

A semelhança de diversos tipos de crowdfunding com os instrumentos financeiros tradicionais faz com que as operações apresentem, tipicamente, riscos similares a esses instrumentos -salvo em função da escala reduzida dos valores envolvidos.

Por exemplo, como descrito no caso dos empréstimos aos pares, a sistemática dessa operação é que um empreendedor ou uma pequena empresa, ao invés de recorrer a um banco ou similar, contrai um empréstimo através da plataforma on-line, pactuando o pagamento de juros e principal junto ao coletivo de contribuidores (credores). Esses credores estão sujeitos ao risco de crédito do/da PMEE em questão e, portanto, podem não receber os juros e o principal investido no projeto ou negócio correlacionado. O mesmo ocorre nas modalidades de empréstimo social - onde não se cobra juros, mas há, em geral, o comprometimento de devolução do principal - e de títulos de dívida.

Neste caso específico, além da possibilidade de inadimplência, a IOSCO (2014: 24) destaca a falta de colateralização e a eventual impossibilidade de acessar os ativos de uma PMEE em caso de não pagamento (default):

"Investing in unsecured loans means that there is no collateral, other than that provided under standard bankruptcy legislation, if the debt goes bad. Even when peer-to-peer lenders specialize in home or business loans, the nature of the 
investment does not necessarily provide access to the borrower's assets in the event of default."

Com efeito, os riscos de default associados potencialmente não são só uma possibilidade teórica. Já existem casos registrados em que o não pagamento dos empréstimos atingiu uma série de investidores:

\begin{abstract}
"When Prosper, one of the largest peer-to-peer lending platforms in the USA, debuted in 2006 it had a low threshold on the creditworthiness of the borrowers able to obtain loans from the platform. [...] It expected lenders to differentiate between investment opportunities through consideration of interest rates, with higher interest rates relating to higher risk investment opportunities. The higher rates of return associated with the less credit-worthy borrowers was compounded by the auction system used by Prosper at the time, which pushed down interest rates as more lenders got involved. The result was industry-wide high default rates, which at times reached 30\% at Prosper." (IOSCO, 2014: 23).
\end{abstract}

Complementarmente, a tabela abaixo, retirada do artigo da IOSCO (2014: 24), ilustra as taxas de inadimplência de algumas plataformas selecionadas:

Tabela 2: Taxa de Inadimplência em Plataformas de Empréstimos aos Pares Selecionadas

\begin{tabular}{|l|c|c|c|}
\hline Plataforma & $\begin{array}{c}\text { Taxa de } \\
\text { Inadimplência }\end{array}$ & $\begin{array}{c}\text { Taxa média de inadimplência } \\
\text { do crédito no país }\end{array}$ & País de domicílio \\
\hline Prosper & $7,0 \%$ & $3,76 \%$ & Estados Unidos \\
\hline Lending Club & $4,3 \%$ & $3,76 \%$ & Estados Unidos \\
\hline Aux money & $2,6 \%$ & $<1,0 \%$ & Alemanha \\
\hline Credit Ease & $2,0 \%$ & $\sim 1,0 \%$ & China \\
\hline Funding Circle & $1,5 \%$ & $0,15-2,6 \%$ & Reino Unido \\
\hline Afluenta & $1,3 \%$ & $1,5 \%$ & Argentina \\
\hline Rate Setter & $0,3 \%$ & $0,15-2,6 \%$ & Reino Unido \\
\hline Zopa & $0,2 \%$ & $0,15-2,6 \%$ & Reino Unido \\
\hline
\end{tabular}

Fonte: IOSCO (2014: 24).

Outro exemplo relevante diz respeito ao equity crowdfunding, divido neste artigo em duas modalidades: a divisão dos lucros e a participação (Tabela 1). Em ambos os casos, o contribuidor visa obter retornos futuros a partir da operação da/do PMEE e do sucesso de seus negócios ou projetos, dependendo, portanto, do sucesso dos mesmos. Há, por conseguinte, três principais tipos de risco inerentes a essas modalidades: o risco de que o projeto ou negócio não prospere, não gerando os retornos almejados nem a distribuição de lucros; o de falência da/do PMEE, que, da mesma forma, não entrega o lucro prospectado; o da não distribuição de lucros pela/pelo PMEE, no caso em que o projeto é bem sucedido, mas a/o PMEE não reparte, devidamente, os lucros obtidos.

No caso da participação, em especial, onde há a compra de uma parcela da titularidade do negócio, tal como no caso de uma ação, os riscos são também relevantes, conforme descrito pela IOSCO (2014: 10): 
"the crowd investors hold equity stakes in the firm and assume all the risks associated with investing in equity. However, being start-ups, these businesses are inherently much more risky as an investment, with market intelligence indicating that there is a $50 \%$ chance of a start-up folding in the first 5 years of existence. Additionally, initial shareholdings in a company can be diluted in value through further issuances."

Além de todos esses riscos, há eminentemente dois tipos de risco que permeiam todas as modalidades de crowdfunding, ainda que sejam mais relevantes em determinadas formas do que em outras: o risco de fraude e o risco da plataforma.

Num ambiente como a Internet, onde o anonimato caracteriza as relações estabelecidas, a possibilidade de fraude é significativa. Problemas relacionados à real identidade dos participantes dos financiamentos coletivos podem gerar consequências negativas tanto para os contribuidores como para PMEEs que levem a cabo suas campanhas. Roubo de identidade, lavagem de dinheiro, financiamento do terrorismo, violação à privacidade e à proteção de dados, isto é, problemas que as instituições e participantes dos sistemas financeiros tradicionais encaram, podem também ser encarados no "mercado" de crowdfunding, novamente, especialmente pela característica dele estar situado num ambiente on-line mais difícil de regular.

O risco da plataforma, por sua vez, também se insere como um risco operacional relevante para os participantes desse mercado, especialmente em relação à segurança dos sistemas e à resiliência das plataformas:

"The platform risk is the risk of a platform being temporarily or permanently shut down. If the platform closes it could put the lenders portfolio of loans at risk of not being repaid as the intermediary position, responsible for the collection of repayment, is unable to be fulfilled." (IOSCO, 2014: 25).

A mencionada resiliência também diz respeito à possibilidade de assegurar que as plataformas tenham sistemas de segurança frente a potenciais ataques cibernéticos que podem - e, num ambiente como a Internet, provavelmente vão - ocorrer. De fato, todas as operações de financiamento coletivo estão sujeitas a essa possibilidade, o que pode gerar uma situação complicada do ponto de vista da confiança de contribuidores e PMEEs em relação ao instrumento.

A Tabela 3 abaixo sintetiza os principais riscos associados a cada modalidade de crowdfunding: 


\section{Tabela 3: Os Diferentes Tipos de Crowdfunding e os Riscos Associados}

\begin{tabular}{|c|c|c|c|c|c|}
\hline \multirow[b]{2}{*}{ Tipo } & \multicolumn{5}{|c|}{ Riscos } \\
\hline & $\begin{array}{c}\text { Fraude e } \\
\text { Risco da } \\
\text { Plataforma }\end{array}$ & $\begin{array}{c}\text { Falha no } \\
\text { desenvolvimento } \\
\text { do produto/ Falha } \\
\text { no projeto }\end{array}$ & $\begin{array}{l}\text { Inadimplência } \\
\text { (default })\end{array}$ & $\begin{array}{c}\text { Não } \\
\text { distribuição } \\
\text { dos lucros }\end{array}$ & $\begin{array}{l}\text { Falência } \\
\text { do negócio }\end{array}$ \\
\hline Doações & $\bullet$ & & & & \\
\hline Recompensas & $\bullet$ & $\bullet$ & & $\bullet *$ & \\
\hline Pré-vendas & $\bullet$ & $\bullet$ & & & \\
\hline Empréstimo Social & $\bullet$ & & $\bullet$ & & \\
\hline $\begin{array}{l}\text { Empréstimos aos } \\
\text { pares }\end{array}$ & • & & $\bullet$ & & \\
\hline Dívida & $\bullet$ & & $\bullet$ & & \\
\hline Divisão dos lucros & $\bullet$ & $\bullet$ & & $\bullet$ & $\bullet$ \\
\hline Participações & $\bullet$ & $\bullet$ & & $\bullet$ & $\bullet$ \\
\hline Híbridos & $\bullet$ & $\bullet$ & $\bullet$ & $\bullet$ & $\bullet$ \\
\hline
\end{tabular}

Fonte: Elaboração própria a partir de DeBuysere et al. (2012: 10-11), Comissão Europeia (2013) e IOSCO (2014). * No caso, não distribuição da recompensa.

Além dos riscos mencionados acima é notável o fato que, diferentemente de um título ou ativo financeiro tradicional, mercados secundários para "investimentos" realizados através de crowdfunding não existem - ou, se existirem, são extremamente restritos. Portanto, a incerteza que se coloca em realização aos investimentos em instrumentos desse tipo não pode ser mitigada através dessa maneira. Ou como destacado pela IOSCO (2014: 27-8):

"Overall, the lack of liquidity is a risk that investors and regulators might want to consider in both equity crowd-funding and peer-to-peer lending. Given the widespread access of these investment choices to retail investors, the implications for unwary investors are clear. Once an investor's money is locked into a contract or has been invested in share equity there is little scope to sell out except at a significant discount to the face value. The lack of liquidity is unlikely to cause systemic risk until the industry grows to a sizeable level."

Em meio a esse contexto, fica claro que o crowdfunding não gera somente benefícios, mas engendra também riscos importantes, que são tipicamente oriundos das relações e mercados financeiros. Se a difusão deste instrumento pode auxiliar na ampliação da funcionalidade do sistema financeiro ao desenvolvimento, garantir que os riscos por ele acarretados sejam mitigados é igualmente importante, para não minar a sustentabilidade desse mercado e os efeitos positivos que ele pode proporcionar na inclusão financeira e na disponibilização de recursos para os agentes. Notadamente, dois pontos se colocam: garantir a confiança dos agentes envolvidos neste mercado em sua resiliência e evitar que o instrumento gere alguma fragilidade financeira relevante dos mesmos.

Nesse sentido, plataformas on-line que intermediam os recursos do crowdfunding necessitam de adotar diversos controles, procedimentos para evitar conflitos de interesse, 
verificação de precificação, técnicas de mitigação de risco e salvaguardas operacionais, especialmente no momento de eleger e selecionar projetos e negócios a serem financiados. Algumas obrigações de divulgação de informação e transparência são também desejáveis. Não há, entretanto, um incentivo forte para que estas plataformas assim o façam, o que nos leva a uma situação em que o público necessita de proteção às falhas tecnológicas, abuso de mercado e fraude.

Isso implica a necessidade premente de implementar ações regulatórias. Como destacado por De Buysere et al. (2012: 33), a regulação é crítica para a "indústria" do crowdfunding e deve abordar diferentes categorias: "operational and financial transparency, security of information and payments, platform functionality, customer protection, and operational procedures".

Para que o crowdfunding entregue seus benefícios apropriadamente, é importante que as campanhas de financiamento sejam reguladas pelas autoridades, assim como as plataformas que fornecem os serviços associados ao financiamento coletivo. Regras de proteção aos clientes/investidores são também necessárias para fornecer a proteção adequada ao público. Em outras palavras, a informalidade característica do crowdfunding (ver Seção 2.2.a) deve, então, ser alterada, de modo que o conjunto de relações derivado dos financiamentos coletivos seja incorporado, através da regulação, a uma rede formal de relações “financeiras".

\subsection{Algumas respostas regulatórias ao redor do mundo}

A Seção anterior deixou claro que o crowdfunding gera diversos desafios regulatórios. $\mathrm{Na}$ prática, muitas das operações de crowdfunding financeiras são classificáveis dentro dos arcabouços nacionais/regionais como instrumentos financeiros tradicionais e, assim, estariam sujeitas à regulação tradicional incidente sobre ofertas públicas, emissores, proteção ao consumidor etc.Contudo, as amarras e o custo regulatório existente podem inviabilizar o modelo de crowdfunding difundido até aqui e fechar a porta de acesso de inúmeros(as) PMEEs aos recursos do público. Nesse sentido, o peso da regulação incidente deve ser calibrado, de forma a não estrangular o mercado nascente e, simultaneamente, mitigar os riscos engendrados pelas operações.

Isso exige o desenvolvimento de regulações específicas, dedicadas ao financiamento coletivo, que leve em conta as idiossincrasias do instrumento e dos riscos por ele acarretados, especialmente, ponderando-os de um ponto de vista sistêmico. É notável que o "mercado" de crowdfunding não tem - pelo menos até o momento - a potencialidade de gerar problemas sistêmicos: "The markets for both peer-to-peer lending and equity crowd-funding are currently so small that they do not pose an immediate systemic risk." (IOSCO, 2014: 45). Mas para que a ampliação da funcionalidade dos sistemas financeiros seja viabilizada, a regulação precisa atuar em 
diversas áreas. Notadamente, três áreas merecem destaque: (i) plataformas; (ii) transparência; (iii) proteção ao investidor.

Alemanha, Austrália, Canadá, Comissão Europeia, Estados Unidos, França, Hong Kong, Itália e Reino Unido implementaram ou estudam implementar medidas específicas em relação ao crowdfunding. Ou seja, algumas respostas regulatórias já existem ao redor do mundo, porém a questão está longe de um consenso.

Uma primeira tentativa de regular o financiamento coletivo consta na Lei de Incentivos a Negócios Nascentes (JOBS Act) americana, publicada em 2012, que dedica seu Título III à matéria. O registro das plataformas (intermediários) e a definição de alguns requerimentos, relativos à divulgação de informações, sigilo dos usuários e prevenção à fraude, dentre outros, são obrigações adiantadas na Lei. Esta, contudo, depende de regulamentação complementar, cuja consulta somente foi disponibilizada pela U.S. Securities and Exchange Commission em 23/10/13 (SEC, 2013).

Há também uma série de limites aplicáveis às campanhas de crowdfunding e aos agentes envolvidos nesse "mercado". Nomeadamente, a regulação impõe um teto máximo para o levantamento de recursos de US\$ 1 milhão (num período de 12 meses), com campanhas acima desse valor sendo reguladas de acordo com as regras convencionais de oferta. Além disso, nem todos as empresas ou empreendedores são elegíveis a se utilizar do instrumento, somente aquelas de menor representatividade econômica. Os contribuidores, por sua vez, se defrontam com limites para os recursos que podem aplicar: grosso modo, estes não devem ultrapassar 5\% ou 10\% da renda anual de indivíduos que recebam, respectivamente, menos ou mais que US\$ 100 mil num ano.

No caso americano, cabe destacar que, em geral, as plataformas não são equiparadas a fundos de investimento nem a aconselhadores (ou consultores) financeiros. Via de regra, desempenham funções específicas, relacionadas à intermediação dos recursos envolvidos no crowdfunding. A Tabela 4 sintetiza as principais medidas regulatórias adotadas nos Estados Unidos. 


\section{Tabela 4: Regulação do Crowdfunding nos Estados Unidos}

\begin{tabular}{|c|c|}
\hline Regime autorizativo & $\begin{array}{l}\text { - Plataforma (funding portal) não necessita se registar na SEC como broker, } \\
\text { mas necessita de autorização da SEC como funding portal; } \\
\text { - Existem descontos regulatórios para funding portals face ao arcabouço } \\
\text { legal de oferta de valores mobiliários. }\end{array}$ \\
\hline Âmbito de aplicação da regulação & $\begin{array}{l}\text { - Funding portals são direcionados para pequenas ofertas e têm que fornecer } \\
\text { aos investidores material educativo, informação sobre o emissor e a oferta, } \\
\text { facilitar a oferta e venda dos títulos adquiridos na plataforma, estabelecer } \\
\text { canais de comunicação e discussão sobre as ofertas e reduzir o risco de } \\
\text { fraude; } \\
\text { - Proibição de realizar recomendações e consultorias financeiras, promoção } \\
\text { de títulos disponibilizados na plataforma e deter recursos dos investidores. }\end{array}$ \\
\hline Principais medidas & $\begin{array}{l}\text { - Companhias apenas estão autorizadas a levantar US\$ } 1 \text { milhão através de } \\
\text { crowdfunding num período de } 12 \text { meses; } \\
\text { - Investidores durante } 12 \text { meses apenas podem investir: (i) maior valor entre } \\
\text { US\$ } 2 \text { mil ou } 5 \% \text { da sua renda ou patrimônio líquido anual para valores de } \\
\text { renda e patrimônio inferiores a US\$ } 100 \text { mil; (ii) } 10 \% \text { da renda anual ou do } \\
\text { patrimônio líquido para valores de renda e patrimônio superiores a US\$ } 100 \\
\text { mil; neste caso, o investimento é limitado a US\$ } 100 \text { mil durante } 12 \text { meses; } \\
\text { - Algumas companhias não são elegíveis para utilizar as exceções do } \\
\text { crowdfunding (e.g. entidades estrangeiras, entidades que já reportam à SEC, } \\
\text { empresas que são alvo de procedimentos de desqualificação, com reportes } \\
\text { irregulares ou que não possuam planos de negócios claros); } \\
\text { - Ações adquiridas via crowdfunding não poderão ser vendidas durante } 1 \\
\text { ano; } \\
\text { - Obrigações de divulgação de informação da companhia junto à SEC (e.g. } \\
\text { transações com partes relacionadas, participação dos órgãos sociais a partir } \\
\text { de } 20 \% \text {, descrição da utilização de recursos da oferta, descrição da situação } \\
\text { financeira e informações financeiras atualizadas, detalhes da oferta como } \\
\text { preço, montante da oferta e objetivos de captação desta); } \\
\text { - Empresas que beneficiem da exceção para ofertar e vender valores } \\
\text { mobiliários têm que remeter relatório anual de atividades à SEC e aos } \\
\text { investidores. }\end{array}$ \\
\hline $\begin{array}{l}\text { Equiparar a gestor de Fundo de } \\
\text { Investimento }\end{array}$ & $\begin{array}{l}\text { - Alguns fundos de investimento auto geridos (Investment Company) são } \\
\text { equiparados. }\end{array}$ \\
\hline
\end{tabular}

Fonte: ANBIMA (2014: Anexo, 3-4).

Abordagem semelhante é utilizada no Reino Unido que foca também na regulação das plataformas. Recentemente, o perímetro regulatório da autoridade britânica - Financial Conduct Authority (FCA) - foi estendido a todas as formas financeiras de crowdfunding, tendo incorporado, a partir de abril de 2014, as operações que caracterizem a realização de empréstimos, como o peerto-peer lending (empréstimos aos pares entre indivíduos) e o peer-to-business lending (empréstimos aos pares entre indivíduos e empresas).

Sobre as plataformas incidem regulações sobre sua conduta, em particular, o regime de divulgação de informações e as campanhas de promoção (promotions), requerimentos mínimos de capital, regras de proteção aos recursos dos investidores e de resolução de disputas. Além disso, no caso específico dos empréstimos aos pares, o regime prevê requerimentos para que as plataformas tomem medidas para assegurar a continuidade da administração dos empréstimos em casos em que saiam do negócio. 
No caso do investment-based crowdfunding, que abarca as modalidades dívida e participação, as regras restringem a oferta de financiamentos coletivos através de plataformas a determinados tipos de investidores, de modo a salvaguardar os investidores em geral dos riscos de investimento em valores não listados (usualmente, oriundos da dificuldade de precificação e iliquidez desses ativos). Somente os seguintes agentes podem participar dos financiamentos coletivos que assumam a forma descrita: (i) clientes profissionais; (ii) clientes de varejo que contam com aconselhamento financeiro; (iii) clientes de varejo classificados como corporate finance contacts ou venture capital contacts; (iv) clientes de varejo certificados como sofisticados ou de elevado patrimônio; e (v) clientes de varejo que confirmem explicitamente que não irão investir mais de $10 \%$ de seu patrimônio nesses produtos.

A FCA propõe também que onde não há aconselhamento financeiro seja aplicado o teste de adequação (appropriateness test) previsto na Diretiva Europeia sobre os Mercados de Instrumentos Financeiros, que institui um procedimento simplificado de verificação da adequação dos produtos ao perfil dos clientes (suitability), restrito à avaliação do conhecimento e experiência dos clientes. A intenção é garantir que as plataformas sejam um efetivo mecanismo de controle do regulador para a proteção dos investidores, evitando que os clientes incorram em riscos que não entendam ou não estejam dispostos a correr. A Tabela 5 resume os principais dispositivos das regras britânicas.

\section{Tabela 5: Regulação do Crowdfunding no Reino Unido}

\begin{tabular}{|c|c|}
\hline Regime autorizativo & $\begin{array}{l}\text { - Se a plataforma permitir a realização de atividades reguladas, tais como, } \\
\text { ofertas de valores e cotas de fundos de investimento, deve ser autorizada pela } \\
\text { FCA; } \\
\text { - Descontos regulatórios face ao arcabouço legal de oferta de valores } \\
\text { mobiliários ou de fundos de investimento. }\end{array}$ \\
\hline Âmbito de aplicação da regulação & $\begin{array}{l}\text { - Autorização de plataformas que permitam levantar capital através da venda } \\
\text { de valores mobiliários não listados ou cotas de fundos de investimento não } \\
\text { regulados (investment based crowdfunding platforms) } \\
\text { - Autorização de plataformas tipo empréstimos aos pares (loan-based } \\
\text { crowdfunding platforms) - a partir de abril de } 2014 \\
\text { - Doações e recompensas não estão sujeitas à regulação da FCA. }\end{array}$ \\
\hline Principais medidas & $\begin{array}{l}\text { - Análise caso a caso do tipo de empresas que pode utilizar investment-based } \\
\text { crowdfunding; } \\
\text { - Algumas ofertas estão apenas disponíveis para clientes profissionais e de } \\
\text { elevada renda que compreendam as especificidades do investimento; } \\
\text { - Descrição apropriada dos riscos de investimento e certificação que clientes } \\
\text { de varejo recebem aconselhamento de entidades autorizadas; } \\
\text { - Não permitir investimentos superiores a } 10 \% \text { do seu montante disponível } \\
\text { para investimento; } \\
\text { - Se não existir aconselhamento por entidade autorizada e certificada, um } \\
\text { teste de adequação terá que ser realizado pela entidade promotora; } \\
\text { - Limitado a ofertas de } € 5 \text { milhões (12 meses). } \\
\text { - No investment-based crowdfunding se a partilha, de lucro não for } \\
\text { canalizada através de uma companhia e/ou acionista, pode ser caracterizada } \\
\text { como fundo de investimento sendo nesse caso proibida a promoção a } \\
\text { investidores de varejo. }\end{array}$ \\
\hline $\begin{array}{l}\text { Equiparar a gestor de Fundo de } \\
\text { Investimento }\end{array}$ & $\begin{array}{l}\text { - Plataformas são equiparadas a gestores de fundos de investimento } \\
\text { alternativo se os mecanismos de partilha de lucro forem diferenciados do } \\
\text { regime societário. }\end{array}$ \\
\hline
\end{tabular}

Fonte: ANBIMA (2014: Anexo, 3-4). 
$\mathrm{Na}$ Alemanha, a regulação tem o mesmo espírito das regulações americana e britânica, mas ainda se encontra menos desenvolvida, inclusive sem uma permissão geral para a realização de empréstimos aos pares - somente em casos específicos tal modalidade é autorizada. Uma particularidade do modelo alemão a ser ressaltada é a necessidade de que PMEEs que se utilizem do instrumento sejam transformadas em sociedades por ações. A Tabela 6 resume as principais medidas.

\section{Tabela 6: Regulação do Crowdfunding na Alemanha}

\begin{tabular}{|c|c|}
\hline Regime autorizativo & $\begin{array}{l}\text { - Se a plataforma de permitir ofertar valores mobiliários ou produtos de } \\
\text { investimento o operador da plataforma que presta serviços financeiros deve } \\
\text { ser autorizado pela Bafin; } \\
\text { - Exceção apenas se o contrato de corretagem abranger apenas produtos } \\
\text { recém-emitidos. }\end{array}$ \\
\hline Âmbito de aplicação da reg & $\begin{array}{l}\text { - Dependendo de sua estrutura, doações e recompensas não são classificadas } \\
\text { como produtos de investimento; } \\
\text { - Transação de títulos alvo de crowdfunding exige licença de serviços } \\
\text { financeiros; } \\
\text { - Modelo de empréstimo aos pares apenas é permitido com empréstimos } \\
\text { subordinados, podendo o financiador se beneficiar de parte dos lucros e } \\
\text { retornos positivos do projeto, mas não sendo responsabilizado por prejuízos. }\end{array}$ \\
\hline Principais medidas & $\begin{array}{l}\text { - Companhias que procuram financiamento têm que se transformar numa } \\
\text { sociedade por ações; } \\
\text { - Limitado a ofertas de } € 100 \text { mil (12 meses). }\end{array}$ \\
\hline $\begin{array}{l}\text { Equiparar a gestor de Fundo de } \\
\text { Investimento }\end{array}$ & $\begin{array}{l}\text { - Start-ups e plataformas não são equiparados a gestores de fundos de } \\
\text { investimento alternativos. }\end{array}$ \\
\hline
\end{tabular}

Fonte: ANBIMA (2014: Anexo, 3-4).

A regulação italiana, por sua vez, traz um elemento extremamente relevante para o propósito delineado para o crowdfunding no presente artigo: ela associa as PMEEs que promovem suas campanhas de financiamento coletivo na Internet ao conceito de start-ups de companhias italianas inovadoras. Isso garante que o instrumento financiamento coletivo seja direcionado exclusivamente a pequenas e médias empresas que levem a cabo projetos de inovação, com efeito, proporcionando uma fonte alternativa de recursos a essas empresas e esses projetos que constam, ambos, na lista de segmentos/setores excluídos dos sistemas financeiros tradicionais e que pela sua reduzida dimensão também não atraem business angels nem venture capital. No caso dos empréstimos aos pares, as plataformas devem ser licenciadas como bancos e estão sujeitas à regulação do banco central italiano. A Tabela 7 resume as provisões: 


\section{Tabela 7: Regulação do Crowdfunding na Itália}

\begin{tabular}{|c|c|}
\hline Regime autorizativo & $\begin{array}{l}\text { - Se a plataforma permitir realizar atividades reguladas tais como ofertar } \\
\text { valores mobiliários (equity crowdfunding) está sujeita a autorização da } \\
\text { Comissione Nazionale per le Societá e la Borsa (CONSOB); } \\
\text { - De acordo com a Lei } 221 / 12 \text { as plataformas devem restringir a oferta de } \\
\text { valores mobiliários a ações de start-ups de companhias italianas inovadoras; } \\
\text { - Descontos regulatórios face ao arcabouço legal de oferta de valores } \\
\text { mobiliários. }\end{array}$ \\
\hline Âmbito de aplicação da regulação & $\begin{array}{l}\text { - Plataformas que operam o modelo de crowdfunding tipo empréstimo aos } \\
\text { pares estão sujeitas às leis do Banco Central. } \\
\text { - Dependendo de sua estrutura, doações e recompensas não são classificadas } \\
\text { como produtos de investimento. }\end{array}$ \\
\hline Principais medidas & $\begin{array}{l}\text { - Plataformas de crowdfunding não poderão funcionar como gestores de } \\
\text { fundos de investimento alternativo exceto se já se encontrarem autorizadas } \\
\text { para essa atividade ou para o de outras atividades de intermediação; } \\
\text { - Condições para uma empresa ser considerada de start-ups de companhias } \\
\text { italianas inovadoras limita muito o tipo de entidades que podem utilizar } \\
\text { equity crowdfunding; } \\
\text { - Limitada a 5\% o investimento de investidores institucionais a uma emissão } \\
\text { de equity crowdfunding; } \\
\text { - Obrigações de divulgação de informação sobre o gestor do portal fixadas } \\
\text { em regulamento; } \\
\text { - Obrigações de divulgação de informação da companhia ao investidor (e.g. } \\
\text { risco de perda de capital, o risco de liquidez do investimento, o risco de não } \\
\text { ter acesso ao dividendo antes da companhia ser uma start-up inovadora, } \\
\text { plano de negócios detalhado); } \\
\text { - Investidores de varejo antes de realizarem investimento tem que provar que } \\
\text { tiveram acesso à informação sobre educação do investidor no sítio da } \\
\text { CONSOB, preencher um questionário onde afirmam compreender os riscos } \\
\text { do investimento e possuírem capacidade de perda do investimento; } \\
\text { - São fixados limites anuais de investimento em crowdfunding que } \\
\text { excepcionam a atividade de serviço de investimento. } \\
\text { - limitado a ofertas de } € 5 \text { milhões (12 meses); } \\
\text { - Condições da oferta deverão ser descritas. }\end{array}$ \\
\hline $\begin{array}{l}\text { Equiparar a gestor de Fundo de } \\
\text { Investimento }\end{array}$ & $\begin{array}{l}\text { - Se já autorizados pela CONSOB para uma atividade de serviço de } \\
\text { investimento, podem ser equiparados. }\end{array}$ \\
\hline
\end{tabular}

Por fim, no caso da regulação francesa, a opção a ser implementada pela Autoritédes Marchés Financiers (AMF) consiste na equiparação das plataformas não a intermediários em geral, mas a aconselhadores financeiros, implicando obrigações de conduta e organização, a adoção de uma política de gerenciamento e mitigação de conflitos de interesse e a implantação de uma ouvidoria. Obrigações de divulgação de informações e transparência também são previstas na proposta regulatória, tal como sintetizado na Tabela 8 abaixo. 


\section{Tabela 8: Regulação do Crowdfunding na França}

\begin{tabular}{|c|c|}
\hline Regime autorizativo & $\begin{array}{l}\text { - Consultores de investimentos coletivos (conseillersen investissement } \\
\text { participatifs) são autorizados pela AMF e enquadrados no arcabouço } \\
\text { regulatório como prestadores de serviços de investimento; } \\
\text { - Existem descontos regulatórios face ao arcabouço legal de oferta de valores } \\
\text { mobiliários. }\end{array}$ \\
\hline Âmbito de aplicação da regulação & $\begin{array}{l}\text { - Criada a figura de consultores de investimentos coletivos como entidades } \\
\text { que exercem uma atividade habitual de consultoria de investimentos em } \\
\text { ofertas de valores mobiliários realizada exclusivamente através de um site; } \\
\text { - Proibição de detenção dos recursos dos investidores. }\end{array}$ \\
\hline Principais medidas & $\begin{array}{l}\text { - Consultores de investimento coletivos devem: (i) estar sediados em França; } \\
\text { (ii) obedecer a critérios de idoneidade e competência profissional; (iii) } \\
\text { cumprir regras de conduta e organização; (iv) aderir a uma associação } \\
\text { profissional devendo a atividade e código de conduta desta ser aprovado pela } \\
\text { AMF; (v) possuir uma política de gestão de conflitos de interesse; (vi) adotar } \\
\text { um mecanismo de tratamento de reclamações (ouvidoria); } \\
\text { - Ofertas realizadas por meio de uma plataforma não precisam de prospecto } \\
\text { de emissão; } \\
\text { - Companhias apenas estão autorizadas a levantar até € } 300 \text { mil via } \\
\text { plataforma, num período de } 12 \text { meses; } \\
\text { - Obrigações de divulgação de informação do consultor de investimento } \\
\text { coletivo ao investidor (e.g. risco de perda de capital, o risco de liquidez do } \\
\text { investimento, risco de não valorização do investimento, remuneração } \\
\text { recebida da companhia, como acompanha o projeto); } \\
\text { - Obrigações de divulgação de informação sobre o gestor do portal fixadas } \\
\text { em regulamento (e.g. detalhes das taxas cobradas pelos serviços prestados); } \\
\text { - Informações aos investidores deveram ser disponibilizadas de forma visível } \\
\text { na plataforma e em linguagem não técnica; } \\
\text { - Sem consentimento prévio do investidor não poderá ser utilizada } \\
\text { informação cadastral deste; } \\
\text { - Associação de consultores de investimento coletivo tem que prestar um } \\
\text { relatório anual da sua atividade à AMF. }\end{array}$ \\
\hline $\begin{array}{l}\text { Equiparar a gestor de Fundo de } \\
\text { Investimento }\end{array}$ & $\begin{array}{l}\text { - Start-ups e plataformas não são equiparados a gestores de fundos de } \\
\text { investimento alternativo. }\end{array}$ \\
\hline
\end{tabular}

Fonte: ANBIMA (2014: Anexo, 3-4).

As iniciativas regulatórias destacadas acima, embora difiram, de certo modo, em termos da abordagem utilizada e do grau de desenvolvimento de cada uma, apontam positivamente para a necessidade de desenvolver um arcabouço dedicado ao tratamento do crowdfunding, conforme advogado no início desta Seção. Em outras palavras, este entendimento parece ser alvo de consenso, ainda que as abordagens implantadas sejam distintas.

Os exemplos acima descritos corroboram as três áreas de atenção que devem ser abordadas pela regulação: (i) plataformas; (ii) transparência; (iii) proteção ao investidor.Tais áreas contemplam os diversos tipos de risco que os financiamentos coletivos engendram: inadimplência, participação, fraude e de plataformas. Vale mencionar que o foco da regulação no intermediário, isto é, nas plataformas, se revela uma opção de potencial eficácia, já que oferece uma possibilidade de abordar diferentes riscos associados ao crowdfunding de uma só vez na regulação, bem como centrar a supervisão num só agente deste mercado. Tal opção acaba também por adicionar as 
relações derivadas do financiamento coletivo, com interesse financeiro, a uma rede formal de relações financeiras.

Destarte, permite-se que o instrumento seja utilizado sem implicar maiores consequências em termos de risco sistêmico e da fragilidade financeira dos agentes, entregando seus potenciais benefícios de forma ponderada, facilitando efetivamente o acesso das/dos PMEEs aos financiamentos em volumes e custos mais amigáveis que os providos pelo sistema financeiro tradicional e fornecendo a segurança necessária para este mercado. Nesse contexto, sob uma perspectiva keynesiana, o crowdfunding pode contribuir efetivamente para a ampliação da funcionalidade do sistema financeiro ao desenvolvimento dos pequenos e médios empreendedores $e$ empresas e, portanto, ao desenvolvimento econômico.

\section{Conclusão: síntese e considerações sobre o Brasil}

Sinteticamente, o principal objetivo deste artigo foi destacar que, em meio à corriqueira disfuncionalidade do sistema financeiro à obtenção de recursos e financiamento por pequenas e médias empresas, reconhecida especialmente por autores de filiação keynesiana, o crowdfunding pode auxiliar pequenos e médios empreendedores e empresas a acessar os recursos de terceiros e levar a cabo suas atividades, projetos e negócios, ampliando a funcionalidade dos sistemas financeiros ao desenvolvimento à medida que o conjunto de relações dali derivado seja incorporado a uma rede formal de relações financeiras - o que pode ocorrer, por exemplo, a partir do reconhecimento das plataformas de crowdfunding como intermediários financeiros.

Esta formalização das relações, que não é originalmente característica do financiamento coletivo aqui definido, se faz necessária à medida que o crowdfunding engendra riscos aos contribuidores e tomadores. A regulação, nesse contexto, serve a este propósito: permite incorporar ao sistema financeiro formal esta prática, porém precisa ser desenhada especificamente para este propósito, de modo a permitir que o crowdfunding entregue seus benefícios e garantir a proteção apropriada aos investidores, sem onerar o instrumento excessivamente, inviabilizando seu modelo.

No Brasil ${ }^{13}$, diversas campanhas de crowdfunding já foram realizadas. Em 2010 foi criado o site Queremos, destinado ao financiamento coletivo de shows; no ano seguinte, foi lançado o portal Embolacha, com o objetivo de viabilizar projetos relacionados à música, assim como os portais Catarse e Idea.me, na área de projetos criativos, e a plataforma Benfeitoria, na área de projetos sociais. Mais recentemente foram lançado os portais Rio +, Kickante, EmVista e Garupa, com objetivos diversos, assim como o sítio Vasco Dívida Zero, que visa quitar os débitos do Club de Regatas Vasco da Gama, clube de futebol do Rio de Janeiro, junto à Fazenda Nacional.

\footnotetext{
${ }^{13}$ Esta digressão, basicamente, reflete a análise desenvolvida pelo autor em ANBIMA (2014: Anexo, 5).
} 
Esses diversos exemplos, contudo, não contemplam as formas financeiras de crowdfunding. Com efeito, o atual regime regulatório brasileiro não trata especificamente do tema e, assim como destacado no caso geral, cria amarras e custos que podem limitar o financiamento coletivo. As formas de dívida e participação podem ser enquadradas na definição de valores mobiliários ${ }^{14}$ e, portanto, estão sujeitas às obrigações relativas às ofertas públicas, ainda que realizadas através da Internet, e os empreendedores/empresas sujeitos às normas incidentes sobre os emissores ${ }^{15}$. Algumas obrigações são simplificadas para empresas de pequeno porte e microempresas, cuja receita bruta anual não supere, respectivamente, $R$ \$ 3,6 milhões e $R \$ 360$ mil, e que sejam registradas no $\mathrm{CNPJ}^{16}$. Nesses casos, a captação é limitada a R 2,4 milhões a cada período de 12 meses e o registro da oferta é dispensado, bem como não é requerida a participação de um intermediário.

Contudo, o relaxamento da regra não desobriga o envio de uma série de informações à Comissão de Valores Mobiliários (CVM) e a elaboração de material publicitário referente à oferta, que deve ser analisado previamente pela mesma. Além disso, dependendo do papel exercido pela plataforma na campanha de captação, esta pode ser enquadrada como intermediário e, assim, estar sujeita a todas obrigações que implicam sobre um intermediário tradicional. Nesse contexto, considerando a regulação aplicável e os registros disponíveis, nenhum crowdfunding com características de valor mobiliário foi realizado até o momento no país - o mesmo se aplica à categoria de empréstimos. Por outro lado, estima-se que, em 2012, cerca de R \$ 10 milhões foram coletados através das formas não financeiras de financiamento coletivo, com previsão de crescimento significativo desse valor em 2013.

Essa situação contrasta com duas características relevantes apresentadas pela economia e sociedade brasileiras. A primeira diz respeito ao limitado acesso às formas tradicionais de financiamento privadas, em termos e custos razoáveis, que pequenos empreendedores e empresas historicamente possuem. A segunda se refere à difusão do uso de mídias sociais no país, que ocupa o terceiro lugar no ranking de usuários do Facebook no mundo e o segundo no caso do Twitter ${ }^{17}$. Disto depreende-se que há um enorme potencial a ser explorado através do crowdfunding no Brasil, proporcionando a inclusão de uma série de agentes marginalizados pelo sistema financeiro tradicional num circuito onde consigam obter recursos para financiar seus negócios e projetos. Assim sendo, desenvolver um arcabouço de regulação compatível com o desenvolvimento do

\footnotetext{
${ }^{14}$ Segundo o inciso IX do Art. $2^{\circ}$ da Lei $\mathrm{n}^{\mathrm{o}}$ 6.385/76, são valores mobiliários "quando ofertados publicamente, [..] títulos ou contratos de investimento coletivo, que gerem direito de participação, de parceria ou de remuneração, inclusive resultante de prestação de serviços, cujos rendimentos advêm do esforço do empreendedor ou de terceiros”.

${ }^{15}$ Ver Instruções no 400/03 e 480/03 e o Parecer de Orientação no 32/05, da CVM.

${ }^{16}$ Artigo $3^{\circ}$ da Lei Complementar ${ }^{\circ} 123 / 06$.

${ }^{17}$ Os Estados Unidos ocupam o primeiro lugar em ambas as redes e a Índia o segundo lugar no caso do Facebook.
} 
segmento, que proteja efetivamente os usuários das plataformas e garanta a integridade desse mercado, deve ser um objetivo a ser considerado pelas autoridades brasileiras.

Recentemente, a Comissão Europeia noticiou que foi estabelecida a criação de um Fórum Europeu de Crowdfunding, que reunirá as partes interessadas no tema através um grupo de experts no assunto, e encomendada a realização de dois estudos, um mais genérico sobre o papel do crowdfunding no sistema financeiro da região e outro relacionado ao potencial do financiamento coletivo para dar suporte financeiro a atividades de pesquisa e desenvolvimento. Reproduzir iniciativas como esta no Brasil pode dar origem a uma importante agenda de pesquisa, que auxilie na ampliação da funcionalidade do sistema financeiro nacional ao nosso desenvolvimento econômico.

\section{Referências}

ANBIMA. "Crowdfunding entra na pauta dos reguladores". Radar ANBIMA n 8. Rio de Janeiro: ANBIMA, 2014.

BELLEFLAME, P.; LAMBERT, T.; SCHWIENBACHER, A. "Crowdfunding: Tapping the right crowd”. CORE Discussion Paper n. 32, 2013.

CARVALHO, F. J. C. "Reformas financeiras para apoiar o desenvolvimento". Textos para Discussão CEPAL-IPEA, 14. Brasília, DF: CEPALE escritório no Brasil/IPEA, 2010.

COMISSÃO EUROPEIA. Communication from the Commission to the Council, to the European Parliament, to the Committee of the Regions, and to the European Economic and Social Committee: An action plan to improve access to finance for SME, 2011.

. "Crowdfunding in the EU - Exploring the added value of potential EU action". Consultation Document, 2013.

. Communication from the Commission to the Council, to the European Parliament, to the Committee of the Regions, and to the European Economic and Social Committee: Unleashing the potential of Crowdfunding in the European Union, 2014.

DE BUYSERE, K; GAJDA, O.; KLEVERLAAN, R.; MAROM, D.A Framework for European Crowdfunding, 2012.

FAMA, E. "Efficient Capital Markets: A Review of Theory and Empirical Work". Journal of Finance 25 (2): 383-417, 1970.

FCA."The FCA's regulatory approach to crowdfunding (and similar activities)". Consultation Paper 13/13. London: FCA, 2013.

GURLEY, J.; SHAW, E. "Financial Aspects of Economic Development”. American Economic Review, Vol. XLV, n 4, September: 515-538, 1955. 
HEMER, J. “A Snapshot on Crowdfunding”, Working Papers firms and regions no.R2. Karlsruhe: Fraunhofer Institut für System- und Innovationsforschung, 2011.

HERMANN, J. Liberalização e Crises Financeiras: o debate teórico e a experiência brasileira nos anos 1990. Tese de Doutoramento, Instituto de Economia da Universidade Federal do Rio de Janeiro. Rio de Janeiro: IE-UFRJ, 2002.

. "Microcrédito como política de geração de emprego e renda: possibilidades e limites," in: Sicsú, J.; Paula, L. F.; Michel, R. (orgs.) Novo-Desenvolvimentismo: um projeto nacional de crescimento com equidade social. Rio de Janeiro: Editora Manole, pp. 271-299, 2005.

. "Bancos públicos em sistemas financeiros maduros: perspectivas teóricas e desafios para os países em desenvolvimento". Revista de Economia Política, vol. 31, n. 3 (123), Jul-Set, 2011.

HOUSE OF COMMONS. "Changing banking for good: First Report of Session 2013-14". Parliamentary Commission on Banking Standards, Volume II: Chapters 1 to 11 and Annexes, together with formal minutes. London: The Stationery Office Limited, 2013.

IOSCO.“Crowd-funding: An Infant Industry Growing Fast”. Staff Working Paper of the IOSCO Research Department. Madrid: IOSCO, 2014.

KEYNES, J. M. A Treatise on Money, in The Collected Writings of John Maynard Keynes, Vol. 5-6. London: MacMillan, 1929.

"Alternative Theories of the Rate of Interest," The Economic Journal, Vol. 47, No. 186, junho, pp. 241-252, 1937a. crossrefhttp://dx.doi.org/10.2307/2225525

. "The 'Ex-Ante' Theory of the Rate of Interest," The Economic Journal, Vol. 47, No. 188, December, pp. 663-669, 1937b. crossrefhttp://dx.doi.org/10.2307/2225323

LEVINE, R. "Finance and Growth: theory and evidence". Paper prepared for the Handbook of Economic Growth. Carlson School of Management, University of Minnesota and the NBER, 2004.

MALKIEL, B. "Efficient Market Hypothesis," in: Murray, P.; Milgate, M.; Eatwell, J. (eds.) The New Palgrave Dictionary of Money and Finance, London: The Macmillan Press Limited, 1992.

\section{MASSOLUTION. 2013 CF Crowdfunding Analysis Report, 2013.}

MCKINNON, R. Money and Capital in Economic Development. Brookings Institution, 1973.

MINDS. Finance for Development: Financial System and Its Functionality for Development - A Case Study of Brazil and India Focusing on Finance for Innovation and the Role of Development Banks, Pillar 1 Report, mimeo, 2012.

MINSKY, H. P. "Financial Crisis, Financial Systems, and the Performance of the Economy," Research Studies Prepared For The Commission On Money And Credit, Research Study Two. Hyman P. Minsky Archive, paper 232, 1960.

. "The Financial Fragility Hypothesis: An Interpretation of Keynes and an Alternative to 'Standard' Theory" in Minsky, H. P. Can it Happen Again? Essays on Stability and Finance. New York: M. E. Sharpe, Inc, pp. 59-70, 1982.

Stabilizing An Unstable Economy. Yale University Press, 1986. 
"The Financial Instability Hypothesis," The Jerome Levy Economics Institute of Bard College Working Paper no. 74, 1992.

MONTANI MARTINS, N. Bancos de Desenvolvimento e Desenvolvimento Financeiro: uma Avaliação do Caso Brasileiro entre 2000 e 2011. Dissertação de Mestrado, Instituto de Economia da Universidade Federal do Rio de Janeiro, 23/11/2012, 2012a.

. "Sistemas Financeiros, Funcionalidade e Desenvolvimento Econômico: A Experiência do Governo Lula (2003-2010)". Textos para Discussão do Instituto de Economia da Universidade Federal do Rio de Janeiro, nº 9, Dezembro. Rio de Janeiro: IE-UFRJ, $2012 b$.

NERI, M.; MEDRADO, A. Experimentando Microcrédito: Uma Análise do Impacto do CrediAmigo sobre acesso a crédito. Rio de Janeiro: Escola de Pós-graduação em Economia da Fundação Getúlio Vargas, 2005.

NERI, M. (coord.) Microcrédito, Dinâmica Empresarial e Mudança de Classe: O Impacto do CrediAmigo. Rio de Janeiro: FGV/IBRE, CPS, 2008.

PAULA, L. F.Sistema Financeiro, Bancos e Financiamento da Economia: Uma Abordagem Keynesiana. Rio de Janeiro: Editora Campus/Elsevier, 2014.

PAULA, L. F.; HERMANN, J. "Economic Development and the Functionality of the Financial System in Brazil". Anais do IV Congresso Internacional da Associação Keynesiana Brasileira. São Paulo: AKB, 2011.

SEC. Crowdfunding. Proposed Rule (Rules Governing the Offer and Sale of Securities Through Crowdfunding Under Section 4(a)(6) of the Securities Act), 78 Federal Register 66428, 2013.

SHAW, E. S. Financial Deepening in Economic Development. New York: Oxford University, 1973.

SNOWDON, B.; VANE, H. R. Modern Macroeconomics: its Origins, Development and Current State. Cheltenham: Edward Elgar, 2005.

STIGLITZ, J. "Financial Markets and Development," Oxford Review of Economic Policy, 5 (4), 1989.

. "The Role of the State in Financial Markets". Proceedings of the World Bank Annual Conference on Development Economics, 1994.

STUDART, R. Investment Finance in Economic Development. London and New York: Routledge, 1995.

. "The Efficiency of Financial Systems, Liberalization, and Economic Development".

Journal of Post Keynesian Economics, vol. 18, n. 2 (Winter), pp. 269-292, 1995-1996.

YUNUS, M. Banker to the Poor: Micro-Lending and the Battle Against World Poverty. Public Affairs, 2003. 